\title{
Communication in the face of death and dying - how does the encounter with death influence the patient management competence of medical students? An outcome-evaluation
}

\author{
T. Thyson ${ }^{1,2^{*}}$, M. Schallenburger ${ }^{1,2^{*}}$, A. Scherg ${ }^{1}$, A. Leister ${ }^{1}$, J. Schwartz ${ }^{1}$ and M. Neukirchen ${ }^{1,3}$
}

\begin{abstract}
Background information: As part of an elective course, the Interdisciplinary Centre for Palliative Medicine at Duesseldorf University Hospital offers medical students the opportunity to personally meet and talk to a seriously ill patient on one or more occasions. The future physicians are provided with an opportunity to broaden their professional competence, i.e. their knowledge and skills in patient-centred communication at the end of life, and enhance their personal competence, for example in how to professionally handle their own emotions. A topical e-learning module helps the students to prepare for the meetings, and writing a reflection paper forms the basis for the concluding reflection seminar.
\end{abstract}

Objectives: The study's objective is a global and outcome-based evaluation of the elective blended-learning course that provides real-world patient interaction. The outcome-based evaluation or outcome assessment aims to objectively evaluate changes identified in knowledge, skills and attitude among the participants of the elective-course. Furthermore, the evaluation aims to answer the question of whether changes especially in attitude (social skills and self-competence) should be expected after the students have met with severely ill or dying patients.

Method: On two questionnaires specifically developed for this survey the students were able to provide a global rating of the elective course and describe their learning gains in palliative care. The students' learning gains were measured by means of 14 items reflecting the specific educational objectives of the offered elective course. Using the German school grading system as a rating scale, the students assessed their learning progress by retrospectively evaluating their skills before and after completion of the elective course (Comparative Self-Assessment, CSA).

Results: In the time from April 2018 till March 2020, 62 students participated in the evaluation. Overall, learning progress among students could be observed across all areas of competence, and in $50 \%$ of all retrospective self-assessment items the learning gains were $\geq 50 \%$. The highest learning gain (63.6\%) was observed in the students'ability to meet a severely ill patient without fear. The lowest learning gain was observed when students had to confront and accept their own mortality.

\footnotetext{
*Correspondence: tabea.thyson@med.uni-duesseldorf.de; manuela. schallenburger@med.uni-duesseldorf.de

${ }^{2}$ University Hospital Duesseldorf, Interdisciplinary Centre for Palliative

Medicine, Moorenstr. 5, 40225 Duesseldorf, Germany

Full list of author information is available at the end of the article
} original author(s) and the source, provide a link to the Creative Commons licence, and indicate if changes were made. The images or other third party material in this article are included in the article's Creative Commons licence, unless indicated otherwise in a credit line to the material. If material is not included in the article's Creative Commons licence and your intended use is not permitted by statutory regulation or exceeds the permitted use, you will need to obtain permission directly from the copyright holder. To view a copy of this licence, visit http://creativecommons.org/licenses/by/4.0/. The Creative Commons Public Domain Dedication waiver (http://creativeco mmons.org/publicdomain/zero/1.0/) applies to the data made available in this article, unless otherwise stated in a credit line to the data. 
Conclusions: The offered elective course supports students in achieving social and self-competence development goals. According to the obtained results, contact with real-world patients helps mould the students' attitude.

Keywords: Communication at the end of life, Blended learning, Meeting with real-world patients, Palliative medicine

\section{Introduction}

"Professional competence is the habitual and judicious use of communication, knowledge, technical skills, clinical reasoning, emotions, values, and reflections in daily practice for the benefit of the individual and community being served" ([1], page 226). Professional skills such as these are in high demand in the sensitive field of palliative care because it involves the treatment of severely ill and dying patients, a situation that often gives rise to difficult conversations. Therefore, palliative-medicine learning contents should be designed to teach the required knowledge, skills and attitude [2] and use different teaching formats. Such formats can include e-learning, accessible via a platform, and designed to teach the necessary knowledge and skills by means of various didactic methods. Former evaluations found that e-learning, in addition to learning gains in knowledge and skills, can also produce changes in attitude [3]. Students value training in palliative care skills, and they especially value the personal meetings with severely ill and dying patients and their relatives $[4,5]$. A systematic evaluation of the effectiveness of blended learning formats indicated that such meetings can improve the medical students' clinical skills and their capacity for reflection [6]. Real -world patient interaction plays a key role in developing those clinical and communication skills [7-9]. The value of involving patients as a positive contribution to basic as well as advanced medical training is already widely recognised. Patient interaction has become an integral part of teaching, learning, and assessment methods [10].

For acquiring complex communication skills like nonverbal communication and empathy, video interaction with real-world patients has proven superior to simulated interaction [11]. Compared to simulated interaction, medical students consider interaction with real-world patients as more instructive and authentic, although simulated interaction can prepare students for real-world situations in that it helps them to develop their communication skills, thereby strengthening their self-confidence [12]. Bokken et al., [12] also provide guidance concerning the decision under which circumstances real-world or simulated interaction should be preferred. Especially in the final phase of medical training, forms of training including both approaches help students rehearse how they should handle difficult situations (e.g., delivery of painful news, dealing with angry patients). In earlier phases of their medical training, their still low levels of clinical skills and knowledge about patient behaviour makes it difficult for the students to develop a professional persona [13]. Furthermore, internal and external aspects of the learning environment are of importance. Where medical training includes more bedside time, students are more willing to learn about end-of-life care, which has a positive impact on the perceived quality of training. In contrast, subliminal negative messages about palliative care from healthcare professionals and patients and their relatives can negatively impact learning [14].

The research quoted in the introduction above show that in later phases of medical training both interaction with real-world patients as well as blended learning can improve the medical students' clinical and communication skills. At present, there is no published systematic evaluation of changes in knowledge, skills and attitude brought about by palliative care teaching formats that combine real-world patient interaction with blended learning. The objective of this study is a global and outcome-based evaluation of the elective blended-learning course that provides contact with real-world patients. The outcome-based evaluation or outcome assessment aims to objectively evaluate changes in knowledge, skills and attitude among the participants of the electivecourse. Furthermore, the study aims to answer the question of whether changes especially in attitude (social skills and self-competence) should be expected after the students have met with severely ill or dying patients.

\section{Method \\ Approach and participants}

To meet the many different training needs of new medical students, the Interdisciplinary Centre for Palliative Care at Duesseldorf University Hospital offers students in the clinical training phase a blended e-learning course that includes real-world patient interaction. Each semester, 16 students of human medicine are admitted for participation in this elective course. The course includes preparatory e-learning followed by real-world interaction with patients and concludes with a reflection phase. Throughout the semester-long elective course, instructors are available to answer the students' questions. In the first 4 weeks of the elective course, the participants engage in e-learning with video-based best practice examples. Course participants can study six e-learning modules that cover the following topics: communication at the end of life; dealing with and assumptions about 
death and dying, and grief. Some of the best-practice videos feature real patients, while others show actors and actresses simulating patients. Besides professional care providers, some of the conversation partners are also students, apprentices/trainees and pupils from other healthcare occupations whom elective-course participants may know and be able to identify. This phase makes it possible for medical students to prepare individually and in their own time for meetings with patients and their relatives. In addition, students are taught factual and application know-how on relevant communication techniques and models. These contents are provided as digital records. Video-based contents and questions designed to encourage reflection on how participants handle their own emotions and attitudes towards dying and death target the affective learning plane, i.e., the students' personal competence. There are indications that e-learning in palliative medicine exposes attitude-related issues and leads to changes in attitude on 'palliative thinking' [15]. In the second phase, participants meet severely ill patients in palliative care and their relatives. The students meet one patient each and can talk to them on one or more occasions, provided that more than one meeting is possible and feasible for both parties. During the semester, students can get support in personalised 1:1 or small-group meetings to discuss the experiences they made in this phase. In the third or follow-up phase the students write a reflection paper that forms the basis for discussion in the subsequent reflection seminar. In this seminar, the students discuss their meetings with patients with their instructors and reflect on their experience.

In the time from April 2018 till March 2020, at the end of each term, i.e., after completing the elective course, all 62 students who had enrolled in the described elective course were invited to participate in this evaluation. Exclusion criteria for participation in the evaluation were completion of the course prior to the designated time and an age $<18$ years as well refusal to participate voluntarily. The study included a global teaching evaluation and a specific outcome evaluation. The global teaching evaluation was intended to only evaluate the elective course itself along with its content, structure, and didactic implementation. The specific learning gains were measured using the post-then procedure (i.e., the retrospective comparative self-assessment). All participants gave their informed consent for participation in the study. The study was approved by the ethics committee of Heinrich Heine University Duesseldorf. Data were collected electronically with the Surveymonkey ${ }^{\circledR}$ software.

\section{Measures}

The structured questionnaire for this study included 29 items and was developed specifically in German language. The learning goals of Palliative Medicine, a mandatory subject taught in basic medical training, served as a basis for the development of the questionnaire. They include the ten core competences defined by the European Association of Palliative Care (EAPC) [16] and are based on the German Qualification Framework for Lifelong Learning (Deutscher Qualifikationsrahmen für lebenslanges Lernen, DQR) [17]. According to the $\mathrm{DQR}$, learning goals must reflect both professional skills (i.e., knowledge and skills) as well as personal skills (i.e., social skills and independence/autonomy). Independence/autonomy can be considered as attitude and is the ability and willingness to take responsibility for one's own development and adjustment as a person in terms of social, cultural or professional growth. The DQR describes professional and personal skills as so-called professional competences.

The items were discussed and agreed in the Interdisciplinary Centre for Palliative Medicine's multi-professional teaching team, who also checked that the contents were clear and easy to understand.

In addition to demographic information (Items I and II) the global evaluation also included 15 items (see Table 1) enquiring about experience from a prior healthcare occupation (Item III). Items IV and V deal with the e-learning modules and evaluate their suitability for preparing students for meetings with severely ill patients, and enquire about the clarity of the contents. Three items (VI, VII, XI) judge the structure and didactics of the elective course and how it was carried through. Items VIII and IX evaluate the reflection phase. Another three items (XII, XIII, XIV) measure changes in social and self-competence. Two more items serve the purpose of grading the instructors (Item $\mathrm{X}$ ) and measuring overall satisfaction (XV) with the elective course. The students rated items on a five-point Likert scale ranging from "Strongly agree" to "Strongly disagree", where the ratings "Strongly agree" and "Agree" were considered as affirmatives, ie positive responses.

The outcome-based evaluation of the elective course comprises 14 items (see Table 2). Outcomes are based on the students' comparative self-assessment of their learning gains. Comparative self-assessment by students is a valid tool for evaluating medical curricula in terms of specific learning goals [18]. Furthermore, CSA is usually less sensitive for construct-irrelevant parameters than student global assessments [19]. The method is used in outcome-based evaluations. In such evaluations, students are asked to retrospectively assess their former and current levels of performance [20].

In retrospective evaluation, the students rated specific learning outcomes on the knowledge plane (Items 1, 2,10 ), skills plane (Items $3,4,7,8,12$ ) as well as social 
Table 1 Global teaching evaluation items of the offered elective course

\begin{tabular}{|c|c|c|}
\hline Question & Subject & Wording \\
\hline । & Demographics & Gender \\
\hline$\|$ & Demographics & Age \\
\hline III & Experience from prior health-care occupation & $\begin{array}{l}\text { Apart from your medical studies and related internships, have you got any previous expe- } \\
\text { rience gained in another a health-care occupation? }\end{array}$ \\
\hline IV & E-Learning & $\begin{array}{l}\text { The e-learning module is suitable for preparing students for a meeting with a severely ill } \\
\text { patient. }\end{array}$ \\
\hline V & E-Learning & The contents of the e-learning modules are easy to understand. \\
\hline $\mathrm{Vl}$ & Structure & $\begin{array}{l}\text { The structure of the elective course dividing it into e-learning, meeting with a patient and } \\
\text { subsequent reflection is appropriate. }\end{array}$ \\
\hline VII & Implementation & $\begin{array}{l}\text { The lecturers/instructors prepared the meetings between the students and the patients } \\
\text { well. }\end{array}$ \\
\hline VIII & Evaluation of the reflection phase & I found comparing notes during the reflection seminar helpful. \\
\hline IX & Evaluation of the reflection phase & Writing a reflection paper helps me to cope with my meeting with the patient. \\
\hline$x$ & Evaluation of lecturers/instructors & The lecturers/instructors appeared enthusiastic. \\
\hline$X I$ & Didactics & The elective course's didactic design is appropriate. \\
\hline XII & Social and self-competence & The elective course has improved my communication skills. \\
\hline XIII & Social and self-competence & The elective course has changed my attitude towards meeting with dying patients. \\
\hline XIV & Social and self-competence & I felt overwhelmed/out of my depth during my meeting with a severely ill patient. \\
\hline$X V$ & Overall satisfaction & Overall, I am satisfied with the elective course. \\
\hline
\end{tabular}

Table 2 Comparative student self-assessment items rated after completing the offered elective course

\begin{tabular}{lll}
\hline Question & Wording & Competence \\
\hline 1 & I am capable of explaining in detail the basic principles of communication with severely ill patients. & Knowledge \\
2 & I am capable of explaining in detail the NURSE model for dealing with emotions emerging during the meeting. & Knowledge \\
3 & I can actively generate a reassuring atmosphere for my talk with a severely ill patient. & Skills \\
4 & I am confident using non-verbal techniques while talking with a severely ill patient. & Skills \\
5 & I can maintain a neutral attitude in order to professionally handle dying and death in my capacity as a physician. & Attitude \\
6 & I can handle being directly confronted with my own mortality. & Attitude \\
7 & I know how to interpret my dialogue partner's emotions during a meeting. & Skills \\
8 & I have all the skills and competences I need to be aware of my own feelings and maintain a balance between empa- & Skills \\
9 & thy and professionalism while meeting with a severely ill patient. & Attitude \\
10 & I can accept my emotional reaction when sympathising with a patient in an existential crisis. & Knowledge \\
11 & I can explain in detail how my own emotions influence my professionalism and work as a physician. & Attitude \\
12 & I am not afraid of meeting a severely ill patient. & Skills \\
13 & I know how to choose the right words when meeting with a severely ill patient. & Skills \\
14 & I can handle silence in a meeting with a severely ill patient. & Attitude \\
\hline
\end{tabular}

and self-competence plane (Items $5,6,9,11,13,14)$. The 6 -point rating scale was the German school grading system $(1=$ "excellent" till $6=$ "unsatisfactory").

\section{Data analysis}

For the purpose of a global teaching evaluation, a descriptive analysis (frequencies in percent) of the data was performed. The specific learning outcome as measured with comparative self-assessment was determined using the following formula [18]:
CSA gain $[\%]=(($ mvpre-mvpost $) /($ mvpre- 1$)) \times 100$.

mvpre $=$ mean level of self-assessed competence before starting the elective course.

mvpost $=$ mean level of self-assessed competence after completion of the elective course.

\section{Results}

Descriptive statistics

In the time from April 2018 till March 2020 a total of 62 students participated in the global elective course 
evaluation and the specific outcome evaluation. None of the study participants had to be excluded from the global or the specific evaluation because of incomplete data. Almost two thirds (69.8\%) of the participants were female; most students (58\%) were between 20 and 24 years old. Approximately one third (31.1\%) of the students had experience gained in a previous health-care occupation. On average, students accessed the e-learning modules 14.2 times (range: $1-30$ times) and spent a mean time of $6.5 \mathrm{~h}$ (range: $2-20 \mathrm{~h}$ ) with the offered contents.

\section{Global evaluation}

The e-learning part received very positive ratings: $98.4 \%$ of the students found it useful in preparing them for their patient meetings, and all students found the contents easy to understand. All students found the elective course's structure and didactics meaningful and felt that their teachers had adequately prepared them for their meetings with patients $(96.8 \%)$ The students stated that both their communication skills (93.6\%) and their attitude towards dealing with dying patients $(90.3 \%)$ had improved or changed. Overall, $98.4 \%$ of the participants were very satisfied with the elective course.

\section{Outcome evaluation}

According to the outcome-based evaluation the highest learning gains were achieved on the knowledge plane, i.e. the explanation of the NURSE model (Naming, Understanding, Respecting, Supporting, Exploring) [21], skills plane, i.e. the active generation of a reassuring meeting atmosphere, and attitude plane, i.e. the ability to meet a severely ill patient without fear (for details see Table 3). The lowest learning gain was observed in

Table 3 Students'self-reported learning gains, percentage

\begin{tabular}{llll}
\hline Item & Mean value pre & Mean value post & CSA gain \\
\hline 1 & 3.7 & 2.1 & $59.3 \%$ \\
2 & 3.5 & 2.0 & $60.0 \%$ \\
3 & 2.9 & 1.7 & $63.2 \%$ \\
4 & 2.7 & 1.8 & $54.3 \%$ \\
5 & 3.0 & 2.0 & $50 \%$ \\
6 & 2.9 & 2.3 & $31.6 \%$ \\
7 & 2.3 & 1.8 & $38.5 \%$ \\
8 & 2.7 & 1.9 & $47.1 \%$ \\
9 & 2.8 & 2.0 & $44.4 \%$ \\
10 & 2.8 & 2.0 & $44.4 \%$ \\
11 & 3.2 & 1.8 & $63.3 \%$ \\
12 & 3.8 & 2.5 & $46.4 \%$ \\
13 & 2.8 & 1.8 & $55.6 \%$ \\
14 & 1.8 & 1.5 & $37.5 \%$ \\
\hline $\mathbf{N = 6 2}$ & & &
\end{tabular}

the application of non-verbal communication techniques during the meetings. Across all items, the highest learning gains were observed in knowledge, followed by skills, and, finally, social and self-competence (for details see Table 4).

\section{Discussion}

The presented study is an outcome assessment that performs a general teaching evaluation on the elective course and measures a specific learning outcome. The offered elective course helps students to broaden their knowledge and skills and supports them in achieving social and self-competence development goals. Outcomes showed that the combination of real-world patient meetings and digital learning formats can prompt students to change their attitudes.

Overall, the concept of blended learning in the teaching of palliative medicine is rated as positive by the students. The global evaluation shows that students confront, and reflect upon, the topics of death and dying. This outcome matches findings by [6] and supports existing data demonstrating that e-learning is an effective means for acquiring professional competence [22-24]. The existing data also show that e-learning is an accepted method among medical students [22]. The evaluated elective course with real-word patient interaction supports medical students not only in acquiring knowledge and communication skills, it also encourages the development of a personal mindset and emotional engagement with topics like death and dying. The offered course succeeded in reaching the participating students on the attitude plane and resulted in learning gains that prepared them for their future profession and the involved interaction with severely ill patients. This finding supports the research results achieved by [14]. The authors were able to show that a higher proportion of personal patient interaction prompts students to systematically learn about patient care at the end of life. In addition, real-world patient interaction is conducive to the development of interpersonal skills [7-9]. In our study, learning gains were achieved in the domain communication skills, specifically in generating a reassuring atmosphere for the meetings

Table 4 Percentage of learning gains in professional competence according to DQR

\begin{tabular}{|c|c|c|c|}
\hline & \multicolumn{2}{|c|}{ Professional skills } & \multirow{2}{*}{$\begin{array}{l}\text { Personal skills } \\
\text { Social } \\
\text { and self- } \\
\text { competence }\end{array}$} \\
\hline & Knowledge & Skills & \\
\hline Questions & $1,2,10$ & $3,4,7,8,12$ & $5,6,9,11,13,14$ \\
\hline Learning gains & $54.6 \%$ & $49.9 \%$ & $47.1 \%$ \\
\hline
\end{tabular}


with patients. In our opinion, this requires suitable nonverbal communication as well as self-confidence. Hearing directly from the patients how important reassurance is for them in situations like these gives a boost to learning gains. Previous studies showed real-world patient interaction is more effective when students need to learn complex communication skills (e.g. body language) [11]. Furthermore, outcomes also pinpointed those areas of interaction with severely ill or dying patients where young students need special support. This study, for example, found relatively small learning gains in the appropriate interpretation of the patients' emotions (required for feeling empathy). According to the students, however, the level of empathy at this point was already high to begin with, so limits to the extent of learning gains could be expected. Based on the outcome of just one single item, the highest learning gain in this evaluation study was achieved in the domain attitude. After completing the elective course, students were able to meet severely ill patients with much less fear, which was also the reason why they enrolled in the elective course in the first place. In their reflection papers and in the reflection seminars, many students stated that they enrolled in the elective course out of concern about how to address severely ill patients in order to deliver painful news or discuss their situation, and expressed their wish to acquire the necessary skills. During the meetings, the students learned that the patients frequently wanted physicians to be honest, so all involved could have a frank discussion of any issues at hand. This experience can help students build confidence and mitigate fears caused by the challenges that such meetings pose.

However, the highest learning gains across all items were achieved knowledge plane. Previous studies evaluating the use of e-learning with Best-Practice examples in the teaching of palliative medicine found similar outcomes [3]. In this evaluation study, however, the learning gains on the competence plane were even higher. Even though real-world patient interaction appears to be a useful tool for encouraging changes in attitude, the question of which methods are particularly suitable for building social and self-competence remains open due to lack of empirical evidence.

\section{Limitations}

One limitation of this study is its small sample size and the purely descriptive analysis of data. Despite validation of the CSA gain method, the students' comparative self-assessment does not allow a wholly objective evaluation either. Furthermore, a comparison between different sub-groups (e.g., with or without experience from a prior health-care occupation) would have been interesting for result interpretation. Due to the small size of the study population we decided to perform a general analysis and did not define any sub-groups. Given the small number of students participating in this evaluation, a sub-group comparison would not have been representative. For data privacy reasons, we could not perform sub-group analysis on the e-learning modules, either. It is not permitted to simultaneously record virtual e-learning attendance and subsequent evaluation. This means we can see how much time students spend in e-learning but we cannot match evaluation responses to individual persons. All considered, a longer observation period and a significance test as well as validation of the questionnaires used would have helped to make the results representative. In addition, combining a quantitative design with the collection of additional qualitative data could contribute to improved outcome significance. For this purpose, the reflection papers written by the students could be included the evaluation.

\section{Conclusions}

Our evaluation of the offered elective course showed that students achieve learning gains in knowledge, skills and attitude. Furthermore, outcomes also highlighted those areas of interaction with severely ill or dying patients where young students need special support. In the long term, higher-level medical communications skills can potentially improve the doctor-patient relationship and, as a result, improve a patient's quality of life at the end of his/her life.

\section{Abbreviations}

E-learning: Electronic learning technology; CSA: Comparative self-assessment; CSA gain: Comparative self-assessment gain; MS: Manuela Schallenburger; TT: Tabea Thyson; AS: Alexandra Scherg; JS: Jacqueline Schwartz; AL: Anne Leister; MN: Martin Neukirchen.

\section{Acknowledgements}

We would like to thank all students and patients who participated in the present study and Miguel Angel Mendez Delgado for excellent English language editing.

\section{Authors' contributions}

$M S, T T, A S, J S, A L$ and MN developed the structured evaluation questionnaire and were contributors in writing the manuscript. MS designed the digital questionnaire and evaluated the data. All authors read and approved the final manuscript.

\section{Author's information}

The authors work interprofessional and are composed of medical doctors, a nurse scientist and a psychologist.

\section{Funding}

Open Access funding enabled and organized by Projekt DEAL.

Availability of data and materials

The datasets used and/or analysed during the current study are available from the corresponding author on request. 


\section{Declarations}

\section{Ethics approval and consent to participate}

The present study has been performed in accordance with the Declaration of Helsinki and was registered and approved by the ethics board of the Medical Faculty of Heinrich-Heine-University Düsseldorf, Moorenstr. 5, 40225 Düsseldorf (study number 2018-71-ProspDEuA, approved 09.08.2018). All participants gave written informed consent.

\section{Consent for publication}

Not applicable.

\section{Competing interests}

The authors declare no conflicts of interest.

\section{Author details}

${ }^{1}$ Interdisciplinary Centre of Palliative Care, University Hospital, Heinrich Heine University, Duesseldorf, Germany. ${ }^{2}$ University Hospital Duesseldorf, Interdisciplinary Centre for Palliative Medicine, Moorenstr. 5, 40225 Duesseldorf, Germany. ${ }^{3}$ Department of Anaesthesiology, University Hospital, Heinrich Heine University, Duesseldorf, Germany.

Received: 7 May 2021 Accepted: 30 November 2021

Published online: 10 January 2022

\section{References}

1. Epstein RM, Hundert EM. Defining and assessing professional competence. JAMA. 2002;287(2):226-35. https://doi.org/10.1001/jama.287.2.226 Available from: https://pubmed.ncbi.nlm.nih.gov/11779266/.

2. Barclay S, Whyte R, Thiemann P, Benson J, Wood DF, Parker RA, et al. An important but stressful part of their future work: medical students' attitudes to palliative care throughout their course. J Pain Symptom Manag. 2015:49(2):231-42.

3. Schallenburger M. Outcome evaluation of a case-based blended learning format in palliative care teaching. Göttingen: 09:00-10.30 Plenum; 2018.

4. Schillerstrom JE, Sanchez-Reilly S, O'Donnell L. Improving student comfort with death and dying discussions through facilitated family encounters. Acad Psychiatry. 2012;36(3):188-90.

5. Goldberg GR, Gliatto P, Karani R. Effect of a 1-week clinical rotation in palliative medicine on medical school graduates' knowledge of and preparedness in caring for seriously ill patients. J Am Geriatr Soc. 2011;59(9):1724-9.

6. Rowe M, Frantz J, Bozalek V. The role of blended learning in the clinical education of healthcare students: a systematic review. Med Teach 2012;34(4):e216-21.

7. Dickinson BL, Lackey W, Sheakley M, Miller L, Jevert S, Shattuck B. Involving a real patient in the design and implementation of case-based learning to engage learners. Adv Physiol Educ. 2018;42(1):118-22.

8. Graungaard AH, Andersen JS. Meeting real patients: a qualitative study of medical students' experiences of early patient contact. Educ Prim Care. 2014;25(3):132.

9. Mohiaddin H, Malik A, Murtagh GM. Maximizing the acquisition of core communication skills at the start of medical training. Adv Med Educ Pract. 2019;10:727-35

10. Lucas B, Pearson D. Patient perceptions of their role in undergraduate medical education within a primary care teaching practice. Educ Prim Care. 2012;23(4):277-85.

11. Deladisma AM, Cohen M, Stevens A, Wagner P, Lok B, Bernard T, et al. Do medical students respond empathetically to a virtual patient? Am J Surg. 2007;193(6):756-60

12. Bokken L, Rethans J-J, van Heurn L, Duvivier R, Scherpbier A, van der Vleuten C. Students' views on the use of real patients and simulated patients in undergraduate medical education. Acad Med. 2009:84(7):958-63.

13. Vågan A. Medical students' perceptions of identity in communication skills training: a qualitative study. Med Educ. 2009;43(3):254-9.

14. Billings $M E$, Engelberg $R$, Curtis JR, Block S, Sullivan AM. Determinants of medical students' perceived preparation to perform end-of-life care, quality of end-of-life care education, and attitudes toward end-of-life care. J Palliat Med. 2010;13(3):319-26.

15. Gibbins J, Williams J, Cooke J, Alder D, Forbes K. Can e-learning help surface or change medical students' attitudes towards palliative care, death and dying? BMJ Support Palliat Care [Internet]. 2012; [cited 2020 Jun 30]; Available from: https://research-information.bris.ac.uk/en/publications/ can-e-learning-help-surface-or-change-medical-students-attitudes-.

16. European Association for Palliative Care (EAPC). Core competencies in palliative care: an EAPC White Paper on palliative care education - part 1 \& 2 [Internet]. 2013. Available from: https://www.eapcnet.eu

17. Bundesministerium für Bildung und Forschung (BMBF). Deutscher Qualifikationsrahmen für lebenslanges Lernen. 2013. Available from: https:// www.dqr.de/media/content/DQR_Handbuch_01_08_2013.pdf

18. Raupach T, Münscher C, Beißbarth T, Burckhardt G, Pukrop T. Towards outcome-based programme evaluation: using student comparative self-assessments to determine teaching effectiveness. Med Teach. 2011;33(8):e446-53.

19. Raupach T, Schiekirka S, Münscher C, Beißbarth T, Himmel W, Burckhardt $\mathrm{G}$, et al. Piloting an outcome-based programme evaluation tool in undergraduate medical education. GMS Z Med Ausbild. 2012;29(3):Doc44.

20. Schiekirka S, Anders S, Raupach T. Assessment of two different types of bias affecting the results of outcome-based evaluation in undergraduate medical education. BMC Med Educ. 2014;14(1):149.

21. Back AL, Anderson WG, Bunch L, Marr LA, Wallace JA, Yang HB, et al. Communication about cancer near the end of life. Cancer. 2008;113(7 Suppl):1897-910

22. Ruiz JG, Mintzer MJ, Leipzig RM. The Impact of E-Learning in Medical Education. Acad Med. 2006;81(3):207-12.

23. Cook DA, Levinson AJ, Garside S, Dupras DM, Erwin PJ, Montori VM. Internet-based learning in the health professions: a meta-analysis. JAMA. 2008:300(10):1181-96.

24. Warnecke E, Pearson S. Medical students' perceptions of using e-learning to enhance the acquisition of consulting skills. Australas med J. 2011 Jun 30;4(6):300-7. Of role models on medical students. J Gen Intern Med. $1997 ; 12(1): 53-6$.

\section{Publisher's Note}

Springer Nature remains neutral with regard to jurisdictional claims in published maps and institutional affiliations.

Ready to submit your research? Choose BMC and benefit from:

- fast, convenient online submission

- thorough peer review by experienced researchers in your field

- rapid publication on acceptance

- support for research data, including large and complex data types

- gold Open Access which fosters wider collaboration and increased citations

- maximum visibility for your research: over $100 \mathrm{M}$ website views per year

At BMC, research is always in progress.

Learn more biomedcentral.com/submissions 